\title{
The Value of Falsetto in the National Vocal Music Singing and Teaching
}

\author{
Xiaoying Guo \\ Department of music, Nanchang Normal University
}

\section{Keywords: Falsetto; National Vocal Music; Value}

\begin{abstract}
There are two kinds of function for all sound voice, the first is true voice, which is from the function of true voice; the second is false voice, which is from the falsetto. The good combination of the two kinds of function can produce good singing. This paper studies on the value of falsetto in the national vocal music singing and teaching systematically and semantically through analyze the advantages and disadvantages of existing definitions for falsetto, to presents the author 's own view: the falsetto is the sound of singing produced by the resonance effect which is formed by the falsetto functional movement of vocal cords and corresponding head resonance. This paper objectively evaluates the advantages and disadvantages of four kinds of voice, which are art true voice, art false voice, natural and false voice connect, natural and false voice mix and list the existing forms of falsetto in the original national singing art category to argument the value of falsetto. This paper redefines the scope of national vocal music: China's national vocal music art include the Chinese songs which are sang by Chinese language(including Chinese minority script ) and bear Chinese style. This paper also discusses the application of falsetto in the National vocal music singing and believes that the proportion of true voice and false voice in the full range should be different in various style vocal music works.
\end{abstract}

\section{Introduction}

Though that person's voice can be divided into true voice and false voice, true and false hybrid, the application of different types of falsetto voice application are also different. Men or women, high or low voice, whether Chinese or foreigners, there are two kinds of function for all sound voice, the first is true voice(chest voice) whose science noun is "weight function ", which is from the function of true voice; the second is false voice(head voice) whose science noun is "light function ", which is from the falsetto. With the development of era, the national vocal music is also developing: bigger work, wider range and richer performance all demand people to improve singing skills to manage the work accordingly.

The main feature on the voice of the Excellent vocal music school of thought is hybrid resonant voice by true and false combined, that is according to the different of voice register, true and false voice permeate each other for certain proportion and be used mixed. In the vocal circles, people have realized the role of falsetto and have use it widely in teaching. But it is not enough, the attention people put on it, especially the deeply research on it, the knowledge of the value of falsetto in the vocal music teaching and singing for the people whose style is "folk singing". And there are few papers to form concentrated academic point of view to discuss falsetto or study on the value of falsetto in the national vocal music teaching systematically and semantically. Some of the papers just mention a thing or two. Therefore, the author would like to argument and summary the significant of the falsetto in the national vocal music singing and teaching on the basis of the precious experience 
of predecessors. Hope that the paper can change people's aesthetic which has already formed to promote the development of Chinese national vocal music.

\section{The Value of Falsetto in the National Vocal Music Singing}

People call it "Artistic voice". The "art true voice" focuses on the real sound, and "Art falsetto" emphasis on falsetto. The so-called "art true voice "and "art falsetto" are decided according to the main proportion of ingredients which can't be pure true voice or pure falsetto. This is the relationship between quantity and quality in dialectics. Anything's major contradictions and major contradictions determine the nature, and only achieving a certain amount of qualitative can change a thing's quality.

When the amount of true voice is much more than the amount of falsetto in the voice, the true voice can decide the quality of the voice, so it sounds like true voice; when there are more and more falsetto permeates until it more than true voice, the quality of voice will be changed. The falsetto can decide the quality of the voice, so it sounds like falsetto. In order to make the singers find different beautiful voice easier, it is necessary to discuss the true voice and falsetto technically. First of all, from the analysis of the voice function of the vocal cords, Stanley's view of "true voice or falsetto" is quite reasonable, but there are also disadvantages. Because the so-called "falsetto" means the voice whose tone quality and tone color are much different from speaking voice. The people maybe think that the light and empty voice which is similar to flute can be called "falsetto". But it is hard to understand that the strong crisp voice produced by vocal cord shortening closer is also called "falsetto" for average people. However, the high true voice and falsetto are not easy to distinguish. For understanding easily, Mr Lin divided the voice of high pitch zone into true voice whistle and falsetto whistle. But, the voice is produced by the vocal cords and the resonance cavity together.

When singing, the vocal cords only send a small pitch. The expressive singing voice with certain volume, tone color should be produced by resonance oscillation and beautification of other parts. Though true and false mixed voice type has pay attention to the true and false sound mixing, but the people whose style is "folk singing" never pay attention to the appropriate proportion in the whole range. They emphasize national lasting appeal and use the true voice in the low acoustic area which makes the voice more colloquial, whitening, harsh and wide. When reaching to loud area, they may not find the falsetto and shout with the true voice or only use the falsetto which affects the expansion of the range, the unity of the register and the quality of the sound. But Chinese opera singing, on the basis of inheriting national vocal music tradition, use some excellent voice of the western school hybrid resonant voice by true and false combined, that is according to the different of voice register, true and false voice permeate each other for certain proportion and be used mixed. In training, true sound need to use the guide the falsetto thought and falsetto need to be enriched by the tone color of the true voice. Combined with the characteristics of the acoustic region, the mixed resonance of the three acoustic regions is formed. In this way, the true voice and falsetto will be mixed which not only solve the problem of voice range, unified register, music performance, but also can retain the charm of the nation.

There are a number of vocalists in the Chinese Opera, such as Han Yanwen, Sun Liying, Cheng Zhi, Liu Weiwei etc, who symbolize the future of Chinese national vocal music and can become the vocal School of the entire Chinese nation. They not only can play foreign opera, but also can play Chinese opera, such as Mo Hong who has played <Cang Yuan> and also has played <Barber of Seville>, but their singing style often is classified as bel canto instead of national vocal music art. There are historical reasons (the intractable of audience aesthetic intractable), development obstacle 
and also has prejudice of study style in academic circles. It is particularly worth mentioning here that the master graduate student of Chinese Conservatory of Music, Wu Bixia, who obtained foreign and domestic top prize respectively by singing foreign opera aria and Chinese folk songs. They not only have the ability to sing folk song with regional style, but also has the strength to sing foreign opera aria. They are neither limited by the sound range, nor limited by regional limitations, and can produce the voice which should be advocated and carried forward by the media and academia. Someone may worry that they will lose the national style. Because the characteristics of the sound is wide range, and the voice is from the nature, and surpassed the nature in training which may leading that there is no obvious grace note on the style to be found. So, there is a problem of learning from folk. The author thinks that as long as the singer's own cultural background is rooted in the soil of the nation and they master all kinds of embellish cavity characteristics, use the hybrid resonance sound and strengthen the consciousness of national vocal music (study national lasting appeal, enunciation, characteristic style, etc.), they will create a richer vocal music art with ethnic flavor.

To achieve good results, the Peking Opera singing uses the method of "breath" commonly. The power of "Breath" makes the abdomen, chest, neck, even the muscles links the vocal all tightly together as a whole to form a solid channel--air channel. In a short time, "breath" plays a role same to hard Qigong which gathers the support power of the glottis under the glottis. It is because of the powerful strength upward always, and control and support the movement of the vocal cords through the control of the fissure, a kind of singing style is formed: singing is not just rely on vocal chords, but on the strength of the body. It is this, our outstanding opera singers can sing. Through the "breath", breath is strengthened to make the larynx stability after lifting and shorten the resonance tube to make sounds almost resonate in the nasopharyngeal cavity (head cavity). At the same time, "breath" can shut all the big glottis up and leave a hole to send breath to form local vibration of the vocal cords function, that is falsetto function state, and also form pitch state which is matched with the head cavity resonance. Therefore, in order to broaden the range when singing and rich the music performance of voice, according to the different of voice register, it is necessary to make the true and false voice permeate each other for certain proportion. The author thinks no matter what kind of work style or voice style, the falsetto should be used throughout to embody the value of falsetto fully. The word of "national vocal music" people usually used is actually aimed at the western vocal music or foreign vocal music.

There is no non-national music in the world, which means the western vocal music is also divided into Italian, German, Russia, France, Northern Europe and Spain, etc. Voices just like musical instrument whose vibration amplitude became bigger from low to high and the frequency become lower. Voice of scientific research shows that the length of the human's vocal cords are different which also proved that the objective law of vocal cords vibration from low to high: it is from whole-vibration to whole-vibration after shortening and then to edge vibration after shortening even to a very tine vibration. In these three types, the vocal cord of true voice type is the longest, widest and thickest. Since the whole-vibration amplitude is larger than the vocal cord of other voice types in the same part. Then it can be asserted that the block vibration amplitude is larger than the vocal cord of other voice types in the same part which means there is strong sense of true voice and it sounds strong, powerful and bright, vigorous and forcible. Therefore, people should make full use of its ontology condition advantages during practice by retaining their true color properly and limiting falsetto seeping into the voice to embody the features of the voice type: powerful, vigorous and forcible and dramatic intensity. In this way, the essential characteristics of the voice may not be 
destroyed when the singer expand the voice to the loud area. The sing using long-term and too much falsetto is even more serious. It may bury the singer's potential by making the voice especially vocal register lose luster, and it even destroy its voice natural coordination function then cause vocal cord diseases such as leakage, deformation. In the process of singing, even if a trained people violate this principle, it will shorten his artistic career of singing.

So, in order to judge a student's voice type, people should measure it overall from macro and micro. On a macro level, people need to follow the law that the true and false voice retain proper proportion in high, medium and low voice; on a micro level, people need to analyze that the proportion in a vocal register for each student, the dimensional restrictions, and need to look back at the student's body condition for judging his type instead of judging it only by singing experience (replacement of one's own voice type) and the aesthetic orientation (understanding of timbre) blindly. Otherwise there will be such an outcome: the singers whose voice type are same to the judge will adapt it and achieve success and win recognition, but the others will be caught in trouble or even led to vocal cords diseases and then can't sing any more. All in all, about the proportion of true and false voice in the whole range, people should not only rely on the teacher's ears for distinguishing, but also rely on the singers' feeling. While teaching, people should eliminate the influence of subjective factors and judge the voice type the students' belong to objectively and carefully. And then, according to the judgment, people can hold proper proportion of true and false voice accurately for students and coordinate their breath and resonance cavity to develop the potential of the students' voice fully and improve the science content of their voice day by day. When singing different works, people should change the singing technique slightly to adapt the work, which means that people should adjust the proportion of the true and false voice and the use of resonance cavity slightly under the general rule to achieve the purpose of performance of the music perfectly as much as possible. In addition to some work of drama, the singing of Chinese national vocal music give priority to the true voice or make the true and false voice mix which limit the singers' range and voice control ability. After the controversy about the indigenous and the foreign, some people use the good method of voice production from the Western for reference boldly-- mixed vocal register singing which can help the national vocal music develop faster by mixing falsetto into the full range on the basis of proper proportion.

\section{Conclusions}

The goal of researching falsetto is using it. Today, no matter what kind of singing, falsetto permeates in the full rang in different degrees and proportion to adapt to the contemporary development of singing art. Personally, falsetto application not only is the objective requirement to rich the scope of program, but also is one of the means of eternal youth voice. In today's vocal circles, To cater to the public's vocal music aesthetic requirements, most of the so called "folk singing" singers pursuit the bright colors of true sound and ignore the use of falsetto. To some extent, this way influences the development of national vocal music. So, the author hopes that this paper can make the vocal circles pay more attention on falsetto to change the old national vocal aesthetic habits of public through media and "the reaction of successful person". At the same time, the vocal music teachers begin to cultivate new audience year after year. In the end, the new national vocal aesthetic of public will be taken by more and more people. Of course, as a long-term and arduous task, it needs the vocal workers' joint efforts to make the Chinese national vocal music more scientific and rationalization. 


\section{Acknowledgements}

Humanities and social science research project in colleges and universities of Jiangxi province:< The Development and Utilization of Jiangxi Music Curriculum Resources >

Project No.: YS1104

\section{References}

[1] Shen Xiang, Vocal Music Teaching Art by Shen Xiang, Shanghai Music Publishing House, Version 1, 1998

[2] Lu Wenqin, Opera Vocal Music Teaching, Beiyue Literature and Art Publishing House, Version 1 ,October, 1991

[3] Lin Junqing, The Scientific Basis of Singing Pronunciation, Shanghai Music Publishing House, Version 1, September, 1962, 10th printing in September, 1999

[4] Feng Baofu, Qi Zhongzheng, Liu Yunbu, The Medical foundation of Singing, Shanghai Science and Technology Press, Version 1, Feburary, 1981

[5] Ju Linqing, The Knowledge Handbook of Vocal Music, Henan People's Publishing House, Version 1, September, 1993

[6] Music,Dance volume of the Encyclopedia of China, The Encyclopedia of China Publishing House, Version 1, April, 1989

[7] Bai Bingquan,The Methods Study of National Singing, Shanxi People's Publishing House, Version 1, December, $19 \%$.

[8] Lu Wenqin, The Vocal Music Art of Beijing Opera, Shanghai Literature and Art Press, Version 1, March, 1984

[9] Wu Peiwen, The Law of Peking Opera Vocal Tchnique and Voice Training, Academic Journal of Central Conservatory of Music, No. 4, 1997

[10] Hu Du, (()I! Shanghai Literature and Art Press, No. 4, May, 1980

[11] Yu Linqing, The Art of singing of Chang Xiangyu, Music Publishing House, Version 1, Feburary, 1964 in Beijing

[12] Shi Lin, Inheritance and Innovation of National Vocal Music Education-The Thinking of History and Current Status of National Vocal Music Education, The Essays of the National Vocal Music Seminar, Page56 